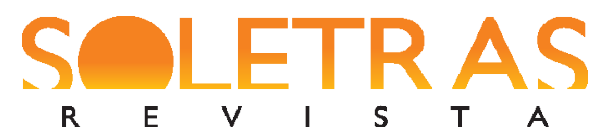

\title{
Entrevista
}

\section{Laboratório de Estudos Experimentais em Linguagem (LEELIN)}

\author{
Mahayana Godoy ${ }^{1}$ \\ Universidade Federal do Rio Grande do Norte
}

\section{Entrevista concedida aos professores Kátia Abreu e Eduardo Kenedy}

Soletras: Quando o seu LAB foi fundado? Qual foi sua experiência em LABs de Psicolinguística anterior à fundação do LAB que coordena?

O Laboratório de Estudos Experimentais em Linguagem (LEELin) é bastante recente. Desde que entrei na UFRN, em 2015, tenho trabalhado com pesquisa experimental com alguns alunos, mas apenas em maio de 2017 o laboratório foi reconhecido institucionalmente.

Antes do LEELin, tive experiência com o Laboratório de Psicolinguística da UFMG, coordenado pela Professora Maria Luiza Cunha Lima e, em menor grau, com os laboratórios do grupo de psicolinguística da Universidade de Maryland. Na Unicamp, onde fiz meu doutorado, minha atuação era mais solitária, uma vez que não havia laboratório constituído para investigação de questões experimentais na psicolinguística. Esse isolamento é bastante ruim para quem desenvolve pesquisa experimental, pois ficamos reduzidos a discutir desenho experimental apenas com o orientador. Minha ida à UFMG para fazer disciplinas do doutorado e, posteriormente, para coleta de dados, foi fundamental não apenas para minha tese, mas também para minha formação. Depois disso, passei a ver a vivência em laboratório como fundamental para a formação do psicolinguista.

Soletras: Quais os principais temas de pesquisa que seu LAB vem contemplando ao longo dos anos?

O LEELin é de criação recente, e sua criação teve como objetivo abarcar a pesquisa de alguns professores que estudam a relação entre linguagem e cognição. Nesse contexto, a área de psicolinguística, sob minha responsabilidade, é uma das três linhas de pesquisa que são desenvolvidas no laboratório. Em psicolinguística, temos investigado principalmente questões

\footnotetext{
${ }^{1}$ Professora adjunta na UFRN. Atua na área de Linguística.mahayanag@gmail.com 
relacionadas ao processamento de informações pragmáticas na compreensão da linguagem. Essas investigações também estão bastante relacionadas a trabalhos que buscam compreender os mecanismos de antecipação que atuam no processamento.

Soletras: Quais as principais técnicas experimentais que vêm sendo empregadas nas pesquisas de seu Lab nos últimos anos?

No momento temos trabalho apenas com técnicas comportamentais, em especial, testes de completação de sentenças, cloze, julgamento de sentenças e experimentos online de tempo de leitura.

Soletras: Você poderia fazer uma estimativa do total de pesquisas de mestrado e doutorado que foram conduzidas no Lab?

Como o laboratório é recém-criado, ainda não tivemos pesquisas de mestrado e doutorado conduzidas no laboratório na área de psicolinguística.

Soletras: O Lab integra alguma rede de cooperação? Poderia citar outros Labs parceiros?

Inicialmente, temos uma rede de colaboração com pesquisadores que fazem parte de outros laboratórios, embora não haja ainda colaboração institucionalmente formalizada com esses laboratórios em si. Há contato direto com colaboradores do Instituto do Cérebro da UFRN, do Basque Center on Cognition Brain and Language e do Laboratório de Psicolinguística da UFMG.

Soletras: Além de trabalhos teóricos de interesse para a área da Psicolinguística, seu Lab desenvolve também pesquisas de interface com a área da Saúde elou da Educação? Se sim, quais?

Uma das linhas do nosso laboratório é a investigação das relações entre aprendizagem e cognição, principalmente mediadas pela linguagem. Quem trabalha nessa linha de pesquisa é a Professora Janaina Weissheimer, que desenvolve pesquisa em transtornos de aprendizagem e em ensino de L2 em contato direto com o Instituto do Cérebro da UFRN.

Soletras: Deixe uma palavra de seu Lab para os leitores alunos de graduação interessados em ingressar na área da psicolinguística experimental. 
Quem está entrando agora na psicolinguística precisa estar atento à interdisciplinaridade que o campo exige. Isso implica em conhecer um pouco de diversas áreas $\ddot{i}$ principalmente estatística, psicologia e neurociências $\ddot{i}$ além de saber se comunicar com especialistas dessas áreas. É preciso ainda ter paciência e saber que novos conhecimentos são gerados apenas após muito trabalho. Quem já está na área há algum tempo sabe que o mais comum é que os experimentos levem a resultados que não se encaixam nas hipóteses levantadas previamente, o que resulta em imenso trabalho de refinamento de hipóteses e/ou do trabalho metodológico desenvolvido.

Além disso, acredito que o aspirante à psicolinguista deva estar sempre atento às discussões metodológicas que acontecem na nossa área e em áreas correlatas. Hoje, por exemplo, há muito debate sobre questões envolvendo reprodutibilidade dos dados, que abarcam revisão sobre viés de publicação, sobre as práticas estatísticas adotadas e até sobre o modelo pago de publicação. Para que nosso trabalho continue relevante, é necessário acompanhar esses debates e irmos ajustando nossa conduta aos consensos que vão sendo construídos.

Essas discussões ocorrem em espaços acadêmicos consagrados da área (por exemplo, o volume 59, n. 4 do Journal of Memory and Language $(2008)^{2}$, dedicado à discussão de novos métodos de análise estatística na psicologia), mas também em redes sociais. De forma dinâmica, vários autores da área discutem essas questões em listas de e-mails, em perguntas do Research Gate, em posts de blogs, no Twitter e no Facebook. Portanto, acho que hoje em dia o psicolinguista deve ter circulação nesses meios para se atualizar sobre essas questões mesmo antes de elas se organizarem em publicações acadêmicas.

Entrevista realizada em 18 de junho de 2017.

\footnotetext{
${ }^{2}$ Disponível em https://www.journals.elsevier.com/journal-of-memory-and-language. 